\title{
Close-contact surveys and mass-screening studies for leprosy in Turkey
}

\author{
A H AYTEKIN* \& T SAYLAN $\dagger$ \\ * Uludağ University Medical School, Department of Community \\ Health Bursa, Turkey; †Istanbul University Medical School, \\ Department of Dermatology, Istanbul, Turkey
}

\section{Accepted for publication 4 November 1987}

\begin{abstract}
Summary Beginning in 1984, the Department of Dermatology at Istanbul University Medical School and the Department of Public Health of Uludag University Medical School embarked on: a, close contact surveys; and b, massscreening studies in the Province of Van in Turkey. Methodology and results are described in detail. The total number of cases in the whole country is unlikely to exceed 4300 and leprosy cannot be considered to be a serious public health problem. However there is room for improvement, notably in compliance to prescribed medication, the reduction of disability rates and the better use of general health units.
\end{abstract}

\section{Introduction}

Beginning in the year 1984, the Department of Dermatology at Istanbul University Medical School and the Public Health of Uludağ University Medical School prepared joint projects aimed at a contemporary solution to the leprosy problem in Turkey.

At the outset the patient's records from original sources were arranged and updated. Incidence and prevalence rates and the actual status of disease in selected areas were ascertained. CARITAS, HEKS, EMMAUS International, the Van and Environs Development Foundation, Istanbul Leprosy Relief Association and other national establishments all helped to realize these endeavours.

\section{Materials and methods}

The Study Group prepared two types of project: 1, close contacts surveying studies; and 2, massscreening studies.

In the first type of project the aim is to visit and examine one by one all patients and close contacts within the province. During the visits treatment of patients is rescheduled according to MDT regimens and social aid is also provided. The new cases among the close contacts are identified according to the clinical form, treatment started according to the WHO standard and they are registered. In Northern and Western Anatolia provinces where the leprosy prevalence rate is high (Muğla, Afyon, Zonguldak), and where the prevalence rate is low (Bursa) all patients and their 
contacts are screened. In Eastern Anatolia provinces, with high prevalence rates (K. Maras, Sivas) all patients and their contacts are screened. These 2 different regions with higher local prevalances when compared with the general prevalence rate, have been selected specifically.

In the second type of project, the people who live in different regions of Van province which has leprosy at endemic levels, mass screening has been applied. Until now, in 5 regions of this province with house-to-house search, about 35,000 people have been examined for clinical manifestations. During these visits not only leprosy cases are considered; help was also given to people who have tuberculosis, malaria, parasitosis and other diseases. In this type of study, known patients also received therapy and social aid, as in the first project.

It is planned that patients and close contacts will be visited at least once in 5 years. In both types of project follow-up, therapy, diagnosis and other aspects of the work are applied according to WHO standards. Drugs and other aids were provided by the project personnel with the assistance of the Ministry of Health. ${ }^{1,2}$

\section{Results}

The results of the same study groups, in regions with different prevalence rates and applying two different methods, are shown below.

\section{CLOSE-CONTACT SURVEY STUDIES}

All patients in 6 provinces are included in this group. The number of registered patients in these 6 provinces was 614 . This represents $16 \%$ of all registered cases in the country. The findings of this population determined during the survey are shown in Table 1.

During the survey a total of 29 patients, 5 female and 24 male, could not be examined because they were temporarily out of the area. Seventy-two patients, 40 female and 32 male, who were taking drugs before examination, were considered completely cured and they were excluded from drug therapy and transferred to the follow-up group.

All patients were receiving only dapsone (not on a regular basis) before the screening. After screening, MDT regimens were started in all patients and they were then entered in the chemotherapy group.

Table 1. Leprosy patients-close-contact screening results

\begin{tabular}{|c|c|c|c|c|}
\hline & \multirow[b]{2}{*}{ Female } & \multirow[b]{2}{*}{ Male } & \multicolumn{2}{|c|}{ Total } \\
\hline & & & No. & $\%$ \\
\hline $\begin{array}{l}\text { Number of registered patients } \\
\text { at the beginning of screening }\end{array}$ & 235 & 379 & 614 & $100 \cdot 0$ \\
\hline $\begin{array}{l}\text { Results of screening: } \\
\text { Deaths }\end{array}$ & $(-) 32$ & $(-) 63$ & $(-) 95$ & $15 \cdot 5$ \\
\hline $\begin{array}{l}\text { Emigrated (left control area): } \\
\text { Out of control } \\
\text { Misdiagnosis }\end{array}$ & 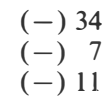 & $\begin{array}{l}(-) 58 \\
(-) 7 \\
(-) 25\end{array}$ & $\begin{array}{l}(-) 92 \\
(-) 14 \\
(-) 36\end{array}$ & $\begin{array}{r}15 \cdot 0 \\
2 \cdot 3 \\
5 \cdot 8\end{array}$ \\
\hline $\begin{array}{l}\text { Number of previously registered } \\
\text { patients af ter screening: } \\
\text { Newly diagnosed cases } \\
\text { Transferred }\end{array}$ & $\begin{array}{r}151 \\
(+) 6 \\
(+) 4\end{array}$ & $\begin{array}{r}226 \\
(+) 7 \\
(+) 6\end{array}$ & $\begin{array}{r}377 \\
(+) 13 \\
(+) 10\end{array}$ & $\begin{array}{r}61 \cdot 4 \\
2 \cdot 1 \\
1 \cdot 6\end{array}$ \\
\hline Latest result of the region & 161 & 239 & 400 & - \\
\hline
\end{tabular}


Eighty-two per cent of all examined patients were considered generally as inactive multibacillary forms (BB, BL, LL). From these patients 173 skin smears were taken with random selection, and it was found that $14(8 \cdot 0 \%)$ had BI $1,8(4 \cdot 6 \%)$ had BI 2 or more.

The rate of disabilities in these examined patients, as grade II or more according to WHO classification, was higher than $65 \%$. Only 1 case was found below the age of 14 in this study and had no disabilities.

\section{MASS-SCREENING STUDIES}

In the last 3 years, 33,458 people were examined in 5 randomly selected regions of Van province. From place to place, with very difficult geographical conditions, all regions were screened house-tohouse with the help of a group of final-year medical students. The results according to the years are presented in Table 2.

The 18 new patients which were identified in the first year, and 3 of 6 patients which were diagnosed in concomitant years, were considered questionable cases at the outset but 1 year later the diagnosis was confirmed and they are registered. For that reason the 24 cases who were diagnosed in the first 3 years, in our opinion, cannot be considered in the incidence rate in calculations for the area. The area in which screening has been completed in the first 3 years should be kept under surveillance for another 5 years and during this period any new cases caref ully recorded.

At the beginning none of these patients had been under MDT regimens. Today about $30 \%$ of them are taking drugs regularly according to the MDT regimens.

The number of cases under 14 years of age are 5 in the whole patient population $(7 \cdot 0 \%)$.

The number of new cases under 14 years of age is $2(8 \cdot 3 \%)$.

In about $60 \%$ of cases, disabilities, WHO grade II or higher, have been observed. They are all in advanced age groups.

The $46 \%$ of cases which were identified during mass-screening are in multibacillary (BB, BL, LL) forms, group. In the patients who were registered in the same region previously this ratio is $74 \%$.

Table 2. The results of mass screening in Van province (Bahçesaray, Çaldiran (1984), Pay-Unseli (1985), Saray (1986) health units)

\begin{tabular}{|c|c|c|c|}
\hline & $1984^{*}$ & 1985 & 1986 \\
\hline Number of examined persons & 15,848 & 8040 & 9570 \\
\hline Previously registered cases in the region: & 49 & $61 \dagger$ & $76 \ddagger$ \\
\hline Deaths & $(-) 7$ & - & $(-) 4$ \\
\hline Left control area & $(-) 7$ & $(-) 1$ & $(-) 3$ \\
\hline Misdiagnosis & $(-) 1$ & $(-) 1$ & - \\
\hline Out of control§ & $(-) 4$ & $(-) 3$ & $(-) 2$ \\
\hline $\begin{array}{l}\text { Number of previously registered patients } \\
\text { after screening }\end{array}$ & 34 & 59 & 69 \\
\hline Newly diagnosed cases & $(+) 18$ & $(+) 4$ & $(+) 2$ \\
\hline Total patients & $52 \dagger$ & $63 \ddagger$ & 71 \\
\hline $\begin{array}{l}\text { Number of patients that completed treatment } \\
\text { as prescribed }\end{array}$ & - & 5 & 22 \\
\hline
\end{tabular}

* For more detailed information see: Lepr Rev, 1986; 57, 243-9.

$\dagger$ The 9 patients have been added who were previously registered in the Pay and Ünseli regions.

$\ddagger$ The 13 patients have been added who were previously registered in the Saray region.

$\S$ Are not discarded from registration. 
As close contacts of patients, 300 people were identified. They were taken under control and examined once in a year. The number of close contacts per patient appears to be $4 \cdot 2$. This figure, when the family structure and number of persons per family are considered together, is however too low. This discrepancy can be explained in two ways; the people who are included in this figure are those who are in close contact with the patient. The close family members who do not live in the same village are not included in this figure. Some families have more than 1 leprosy patient, and close contacts for these families represent 2,3 or even 5 patients. Seventeen $(70.8 \%)$ of 24 newly diagnosed cases who were identified during mass screening belong to these families with a closecontact group.

\section{DISCUSSION}

With two different methodologies, and in areas which has different leprosy prevalence rates, a total of 685 leprosy patients has been studied. This figure represents $17 \cdot 8 \%$ of all leprosy cases in the country.

In the areas where the disease is endemic, there are 1613 registered cases and in the rural portions of these areas, about 2 million people are living. In the region where the prevalence rate is highest $(2 \cdot 08 \% 0$.$) when whole country and area are considered, we perf ormed a mass screening. The rate of$ new cases in close-contact group were $24 \%$ (17 new cases/71 patients) and the rate of new cases which has no contact history is 2 per ten thousand. ( 7 new cases/33, 458 people).

In those areas where leprosy is sporadic, according to 1985 general census, 22 million people are living in rural areas. In these we have 2238 registered cases. In some sampled provinces of these areas mass-screening was performed by us, and we examined 614 registered cases and their families. We found 13 new cases in a close-contact group. The rate of new cases in contact groups in these areas is thus $2 \cdot 1 \%$ and this figure is 12 times less than the figure for the endemic region. If we generalize this ratio, in endemo-sporadic and sporadic regions there are indications that the number of new cases in the close-contact group will be in the region of 47 .

In sporadic and endemo-sporadic regions we have not performed mass screening. For that reason we can not estimate directly the number of new cases in the non-contact group. However, if we apply the same ratio (the ratio of newly diagnosed cases in close-contact groups of two different areas which is 12) to the same areas non-contact groups, and since we have identified 7 new cases in 34,000 people of a high prevalence area with mass screening, and we did not perform mass screening in sporadic, endemo-sporadic areas where $22,000,000$ people are living, we can obtain an approximate number:

$\frac{22,000,000 \times 7}{34,000} \times \frac{1}{12}=377$ new cases for the non-contact group.

If we add all of these figures to the total registered cases, we can say that there could be a maximum of 5090 leprosy patients in Turkey.

However, the survey which has been performed shows that $15.5 \%$ of registered cases had died, and $5.8 \%$ of registered cases are misdiagnosed or have no leprosy at all. For that reason it is possible that the diagnosis in approximately 820 patients of today's registered cases is inaccurate, This could mean that the maximum mumber of leprosy cases should be around 4300 in Turkey. Also our results indicate that unknown leprosy cases in Turkey should be in rural regions and among the adult contacts of patients.

It can be said that the number of patients under the age of 14 is low when compared to the same age group (30\%) for the whole population.

In estimating the number of patients we have taken into consideration the rural areas of population, because $97 \%$ of registered cases are in rural areas.

In summary, when the total number of cases are taken into consideration it cannot be said that 
leprosy is a serious health problem in Turkey. However, there is considerable room for improvement.

1 Patient compliance to the therapy is unsatisfactory. Furthermore many of them are still on dapsone monotherapy.

2 The ratio of patients disabled at grade II or higher, is high. This renders the patients economically 'weak' and requires expensive support including hospitalization.

3 Health units are ideal for leprosy control; their personnel should be educated and encouraged in finding new cases and in the distribution of drugs to patients.

4 There is a high ratio of migration to the cities in Turkey and this includes leprosy patients. We found $15 \%$ of migration among leprosy cases. The registration system should act more rapidly in notifying health authorities about migration.

If we can overcome all of these obstacles, leprosy may well disappear rapidly from Turkey.

\section{References}

1 WHO Study Group. Epidemiology of leprosy in relation to control. Technical Report Series No. 716. WHO: Geneva, 1985.

${ }^{2}$ WHO Study Group. Chemotherapy of leprosy for control programmes. Technical Report Series No. 675. WHO: Geneva, 1982. 


\section{NEWS AND NOTES}

\section{Armauer Hansen Institute, Würzburg, Germany}

The objective of the Armauer-Hansen-Institute results from the targets of the German Leprosy Relief Association (GLRA) and the Medical Mission Institute (MMI).

These are according to the articles of association of the GLRA: all actions aiming directly and indirectly at eradicating leprosy, and their integration into the general health service, particularly by offering; financial support for research and training of personnel; and health information and education.

As laid down by the statutes of the Medical Mission Institute, its main functions are: encouragement of tropical medicine and sociological studies; and conducting medical training courses for missionary personnel and training of physicians and hospital personnel.

In accordance with its objective the Hansen-Institute is divided into two parts, one financed by GLRA, the other by MMI, which are partly interrelated.

The following targets have been agreed upon for these sectors: GLRA: ref erence laboratory for leprosy work in projects; and introduction and improvement of MDT in leprosy and tuberculosis; MMI: teaching laboratory for the development and presentation of adapted technology for health institutions in developing countries; instruction of missionary personnel, technical advisers in developing countries and foreign experts in adapted medical technology; and research on topics in tropical medicine.

The reference laboratory for leprosy focuses on the following areas: performing bacteriological and histological diagnosis, checking the progress of therapy and follow-up.

The following tests are performed: staining and microscopy of skin smears and skin homogenates with the determination of the bacteriological index (BI) and identification of the different morphologicai forms of the bacteria; histological examination of skin biopsies for the classification of the disease; and quality control for those laboratories lacking supervision also in the fields of other mycobacteria, especially of TB.

Training: training of doctors, nurses and lab-technicians doing leprosy work in courses and practical teaching; and elaborating recommendations for the performance of quality controls.

Research: it is intended to meet the requirements of the project countries; its results should be of direct and indirect use for practical leprosy work. Therefore important questions are to be discussed in regular colloquies. These issues should then be pursued and their outcome be published.

Documentation: documentation, in particular of literature not or hardly registered in medical data banks; and availability of the latest findings in leprosy research in an applied form.

Standards and technology in many health institutions in developing countries are too much based on the medical technology of highly industrialized countries. They of ten fail under the poor conditions of rural hospitals.

Laboratory technology there has to be adapted to the following criteria: function in the hands of lesser trained personnel; function without regular supply of electricity and water; little service needed; inexpensive; sufficiently exact; quick; and producible in the respective countries, if possible.

Teaching laboratory: the Medical Mission Institute Würzburg (MMIW) has installed a medical teaching laboratory where methods meeting the criteria mentioned above are collected, developed and presented. The programme has been part of the syllabus of the training courses 'Medicine in Developing Countries' for doctors and nurses at the Institute for Tropical Hygiene of the University of Heidelberg since 1982.

Training: in courses and individual practice doctors, lab-technicians and nursing staff going abroad as well as personnel from overseas are made familiar with adapted laboratory methods.

Research: candidates for a medical thesis work on suitable technologies and topics in tropical medicine.

AIDS-aid: a task force against AIDS in developing countries has been set up with a special team. It works in close cooperation with MISEREOR in Aachen and the German Institute for Medical Mission in Tübingen. It is to adapt Elisa-testing to simple conditions and advise church-related hospitals in saf ety procedures, such as blood transfusion, checking and sterilization and aspects of care of AIDS patients.

Further information: Armauer Hansen Research Institute, Hermann-Schell-Strasse 7, D-8700, Würzburg, P.O. Box 348, Germany.

\section{Bureau for Overseas Medical Service}

The Bureau runs a register for health workers who are interested in working in the Third World and acts as a coordinating agency for a wide range of health posts. It also provides advice and information on prospects for resettlement, runs short basic training courses for working in the Third World and provides information on training opportunities in the UK and Europe. A bi-monthly newsletter and job list is circulated to all members of the register. Details of posts that require filling urgently are sent to members of the register with appropriate qualifications and experience. For more details please contact Jane Lethbridge, Director, Af rica Centre, $38 \mathrm{King}$ Street, London WC2E 8JT, Tel: 01-836 5833. 